\title{
On the Imaginary Geometry
}

\author{
Abdullah Kurudirek, Huseyin Akca \\ Tashkent State Pedagogical University, Tashkent, Uzbekistan \\ Email: drcebir@hotmail.com, huseyinakcha@gmail.com
}

Received 1 June 2015; accepted 16 June 2015; published 24 June 2015

Copyright (C) 2015 by authors and OALib.

This work is licensed under the Creative Commons Attribution International License (CC BY). http://creativecommons.org/licenses/by/4.0/

(c) (i) Open Access

\section{Abstract}

In this paper, we have aimed at showing the available set of points of Lobachevsky axiom by the help of Euclidean plane (As it is known, an Euclidean plane, which is a flat surface with no thickness, extends forever to all directions.), especially on behalf of broadening the horizons in geometry education of high school students.

\section{Keywords}

Axiom, Eyeshot, Lobachevsky Parallelism, Right and Left Parallel

Subject Areas: Geometry, Geometry Education

\section{Introduction}

Bilindiği üzere, ortaokul ve liselerin geometri derslerinde okutulan öklid geometrisinde nokta ile doğru bu düzlem geometrisinin esas kavramlarıdır.

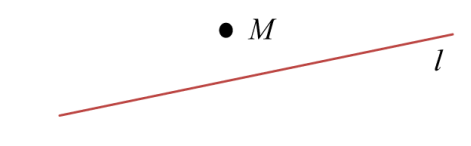

Resim 1. Öklid geometrisinin temeli.

Herhangi bir $M$ noktası $l$ doğrusu üzerinde olursa $M \in l$, doğru $M$ noktasından geçer ve iki nokta doğrunun üzerinde yer alır. Öklid geometrisinde her hangi iki doğru parçası sadece iki durumda bulunabilir.

1. durum: Eğer bu doğruların ortak noktaları varsa kesişirler.

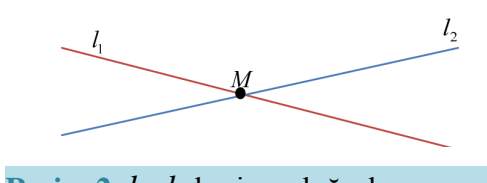

Resim 2. $l_{1}, l_{2}$ kesişen doğrular.

How to cite this paper: Kurudirek, A. and Akca, H. (2015) On the Imaginary Geometry. Open Access Library Journal, 2: e1433. http://dx.doi.org/10.4236/oalib.1101433 
2. durum: Eger $l_{1}, l_{2}$ doğrularının ortak noktaları yoksa bu doğrular kesişmez ve birbirlerine paraleldirler.

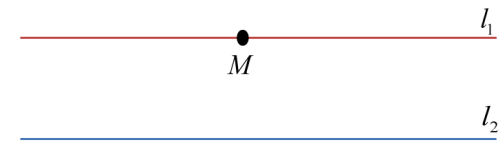

Resim 3. $l_{1}, l_{2}$ paralel doğrular.

$M$ noktası $l$ doğrusunun üzerinde değilse, $M$ noktasından geçen doğru destesi içerisinden sadece bir tanesi $l$ doğrusuna paraleldir.

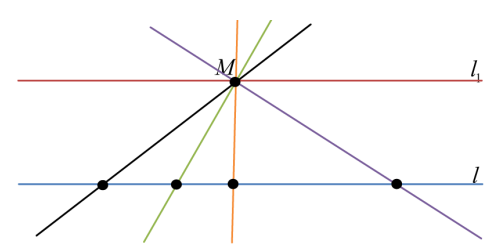

Resim 4. $l, l_{1}$ paralel doğrular.

Yukarıda ifade edilen kavramlar, Öklid geometrisi düzlemi olarak okullarımızda öğretilmektedir. Burada Öklid aksiyomları onun temel esaslarını teşkil eder. 1829 yılında N.I. Lobaçevski, Geometriye bir yenilik olarak paralellik aksiyomunu ilave eder ve kendisinin bu katkısını "Tasavvurdaki Geometri” olarak adlandırır.

$\mathrm{Bu}$ aksiyom (Lobaçevski aksiyomu); Bir doğruya üzerinde bulunmayan noktadan kesişmeyen iki doğru çizilebilir, şeklinde ifade edilir.Amacımız Lobaçevski aksiyomunun geçerli olduğu noktalar kümesini gösterebilmektir. Bunun için sadece Öklid düzleminden faydalanılacaktır. Bilindiği gibi, Öklid düzlemi sonsuz bir şekilde bütün yönlere uzayıp gider.

Her ne kadar, düzlemin tamamını hayal etmemiz mümkün olsa bile bunu görmemiz mümkün değildir. İnsanın görüş imkanı sınırlandırılmıştır. Öklid düzleminin görünebilirliği mümkün olan noktalarını Lobaçevski düzleminin noktaları olarak alalım. Bu düzlemdeki doğruların görme mesafesine giren bölümüne Lobaçevski düzleminin doğruları diye bakabiliriz. Eğer görüşs sahamız daire şeklinde olsa aşağıdaki şekil meydana gelir [1].

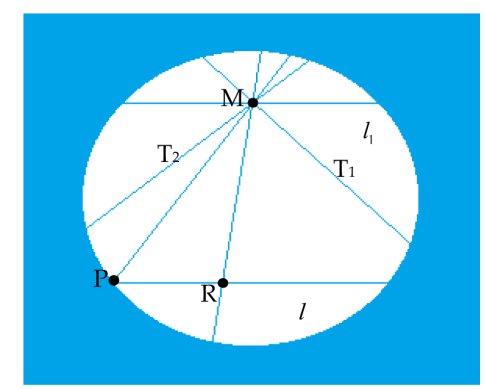

Resim 5. Lobaçevski düzlemi.

Normalde düzlemin mavi boyalı kısmı bize görünmemektedir. Demek ki Lobaçevski düzleminin noktalarına, daire içindeki noktalar ve doğrularına kirişler diye bakacak olursak $T_{1}$ ve $T_{2}$ doğrularının $l$ doğrusuyla kesişmediğini açık bir şekilde görüp söyleyebiliriz. Buradan da Lobaçevski aksiyomunun sağladığını yani söylenen doğrularda $l$ doğrusuyla kesişmeyen $T_{1}$ ve $T_{2}$ doğruları gösterilmiş olur.

Resim 5'deki;

- $\quad M R$ doğrusu $l$ doğrusuyla kesişir.

- $\quad M P$ doğrusu ile $l$ doğrusunun kesişme noktası dairenin kenar noktasında bulunur.

- $l_{1}$ doğrusu $l$ doğrusuyla kesişmemektedir.

Lobaçevski aksiyomundan faydalanarak aşağıdaki teoremler ispatlanabilir.

Teorem-1: Bir doğru üzerinde olmayan herhangi bir noktadan doğru ile kesişmeyen sınırsız sayıda doğru çizilebilir. Bunu aşağıdaki resimde görebiliriz. 


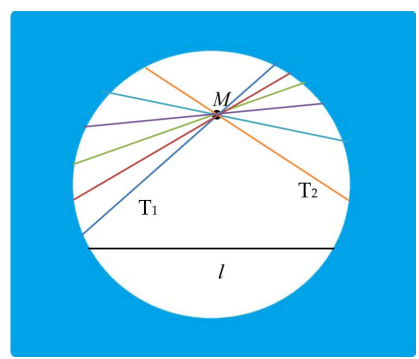

Resim 6. Kesişmeyen doğrular.

Gerçekten; $T_{1}$ ve $T_{2}$ doğruları dışarıda çizilen doğrulardan oluşan dikey açıdan geçen herhangi bir doğru $l$ ile kesişmemektedir. M noktasından geçen doğrular arasında $l$ doğrusu ile kesişen ve kesişmeyen doğrular mevcuttur [2].

Tanım: M noktasından geçen ve $l$ doğrusu ile kesişen ve kesişmeyen doğrular toplamını sınırlayan doğruya $l$ doğrusuna paralel doğru denir. Bu tanım aşağıdaki teoremi doğrulamaktadır.

Teorem-2: $l$ doğrusunun dışında M noktasından l'ye paralel iki doğru çizebiliriz.

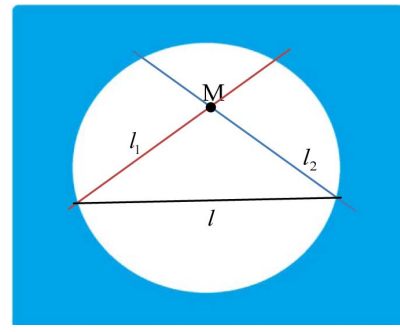

Resim 7. Paralel doğrular.

Paralel doğrular iki türlü olduğundan, bunların farklarını, sağdan paralel ve soldan paralel tanımlarıyla ifade edebiliriz.

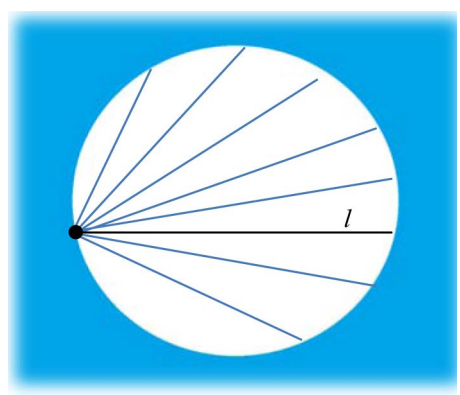

Resim 8. Soldan paralel doğrular.

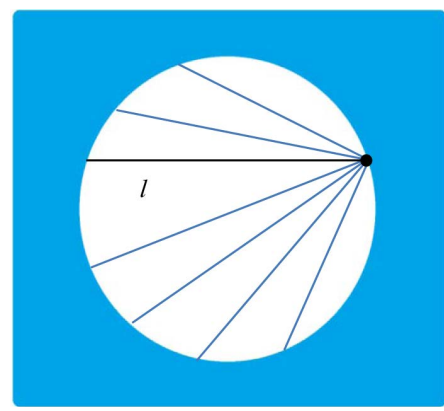

Resim 9. Sağdan paralel doğrular. 
Şimdi verilen bir $l$ doğrusuna sağdan ve soldan paralel doğrular çizelim.

Resim 8 ve Resim 9'da paralel doğrular tasviri, ve Resim 10'da Öklid geometrisindeki paralel doğruların Lobaçevski geometrisindeki ifadesi gösterilmektedir.

\section{Resim 10. Öklid paralelleri.}

Lobaçevski düzlemini ifade edebilmek için görme mesafesini esas almıştık. Resim 10'daki paralel doğrulara sağdan veya soldan bakılırsa Lobaçevski paralelliğini tasavuur edebiliriz. Örneğin, şu demiryolunun ortasından bakınca paralel doğruların uzakta kesişiyor görülmesi gibi.

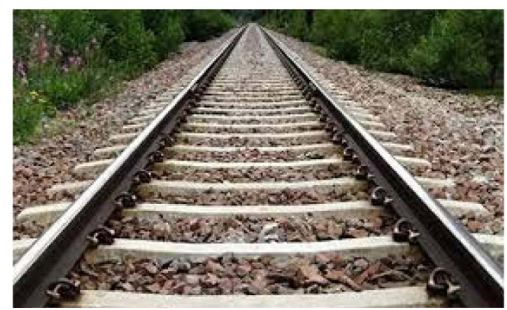

Resim 11. Demiryolunun görünüşü.

\section{Paralelliğin Özellikleri}

Lobaçevski doğrularının Öklid doğrularından farklı olduğu aşağıdaki özelliklerden anlaşılabilinir [3].

1) Eğer $l_{1}$ doğrusu $l_{2}$ doğrusuna paralel olursa $l_{1}$ —den alınan herhangi bir $\mathrm{M}$ noktasından $l_{2}$ ye kadar olan mesafe parallelik yönünde azalır ve ters yönde artar. Öklid düzleminde ise paralel doğrular arasındaki mesafe değişmez.

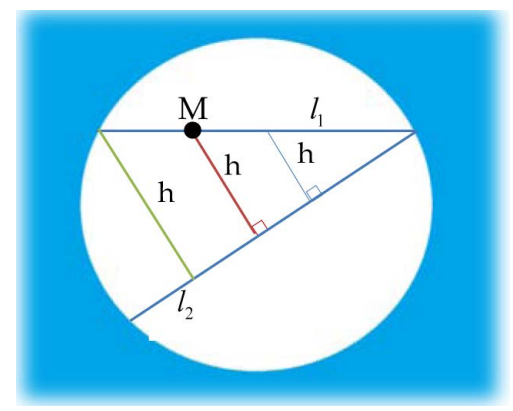

Resim 12. Paralellik mesafesi.

2) Bilindiği gibi Lobaçevski düzleminde herhangi bir doğru, düzlemi iki yarım düzleme ayırır. Bu özellik Lobaçevski düzlemini doğrulamaktadır.
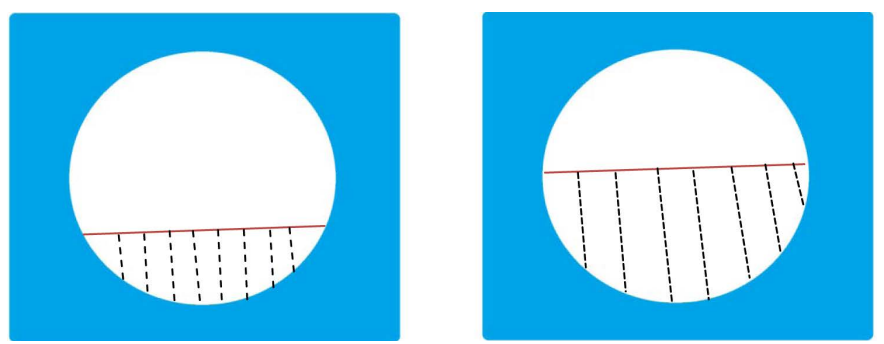

Resim 13. Lobaçevski düzleminin bölünmesi. 
3) Paralel $l_{1}$ ve $l_{2}$ doğruları verilsin $l_{1}$ doğrusundan $l_{2}$ yedik doğrularçizdiğimizde bu dikliklerintabanı $l_{2}$ —de doğruları tam kaplamayabilir.

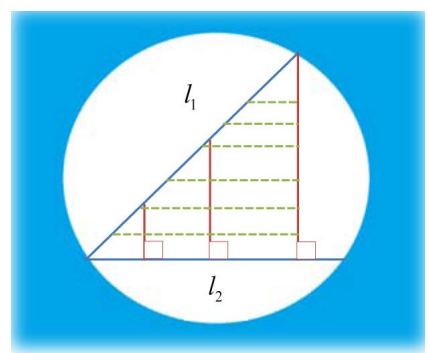

Resim 14. Kaplanmayan alan.

4) Lobaçevski düzleminde üç doğru kesişmesinden meydana gelen şekli üçgen olarak alacak olursak, iki kenarı kendi arasında paralel (Resim 15(A)), iki çift kenarı paralel (Resim 15(B)) ve üç kenarı paralel (Resim 15(C)) üçgenler mevcuttur.

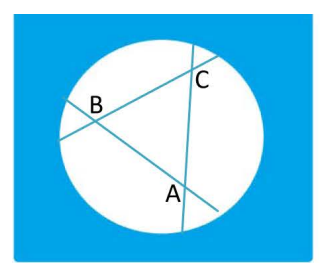

Resim 15. Kesişen Üçgenler.

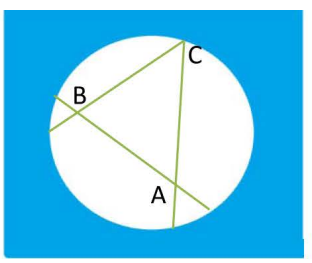

(A)

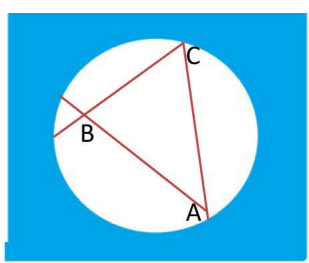

(B)

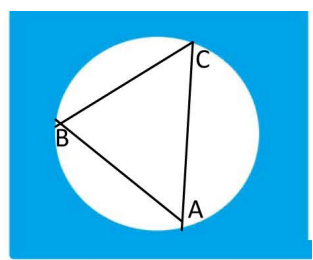

(C)

Lobaçevski düzlemindeki açı ile Öklid düzlemindeki açı kavramları aynıdır.

5) Öklid düzlemindeki paralel doğrular Lobaçevski düzleminde kesişmeyen doğrulardır.

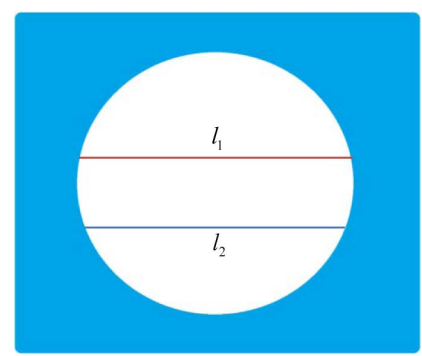

Resim 16. Öklid Lobaçevski paralelleri.

6) $l_{1}$ ve $l_{2}$ Lobaçevski düzleminin kesişmeyen doğruları olsun, bu doğrular için yalnız genel bir diklik mevcuttur ve bu da doğrular arasındaki mesafeyi verir.

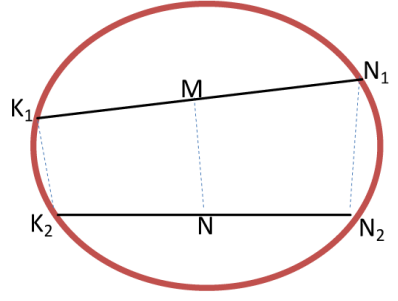

(a)

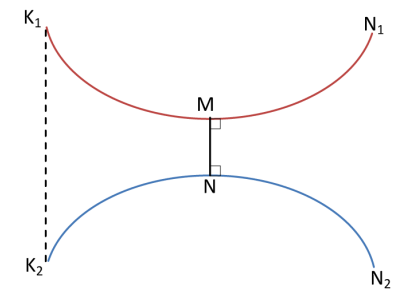

(b)

Resim 17. Lobaçevskide mesafe tasavvuru. 
Lobaçevskinin bu özelliğini anlamak için Resim 17B'yi göz önüne getirmek gerekmektedir. O zaman sınırlanmış MN arasını en kısa mesafe olarak anlamak mümkündür.

7) Lobaçevski düzlemindeki paralelliği göz önüne getirmek için genel asimtota sahip olan bir hiperbol grafiğini tasavvur edebiliriz.

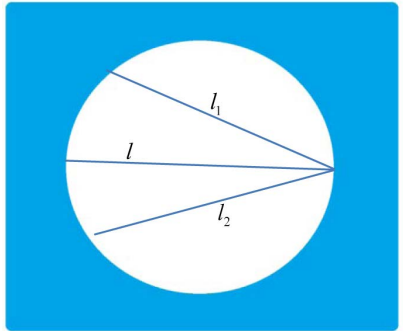

(a)

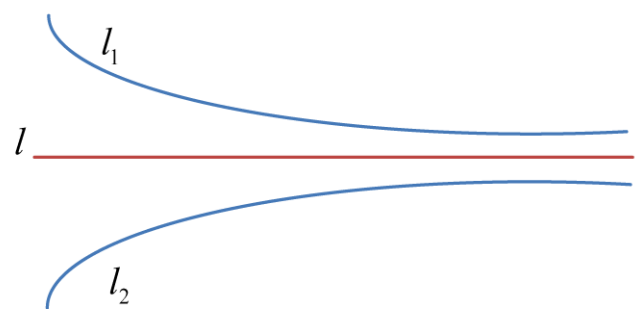

(b)

Resim 18. (A) Lobaçevskide paralellik; (B) Lobaçevskide paralellik tasavvuru.

\section{Sonuç}

Özellikle lise öğrencilerinin geometri derslerinde ufuklarını açmak üzere, bilinen ve yaygın bir şekilde kullanılmakta olan öklid geometrisinden faydalanarak Lobaçevski aksiyomu ve düzlemi öğrencilere izah edilmeye çalışıldı. Özellikle görüş mesafesi kavramından ve demiryolu örneğinden öğrencilerin tasavvurdaki geometri üzerine bakışlarının değiştiği gözlemlenmiştir.

\section{References}

[1] Kurudirek, A., Akça, H. and Erdoğan, M. (2013) On Geometries in Affine Plane. Applied and Computational Mathematics, 2, 127-129. http://dx.doi.org/10.11648/j.acm.20130206.13

[2] Kurudirek, A. and Akça, H. (2015) On the Concept of Circle and Angle in Galilean Plane. Open Access Library Journal, 2, e1256. http://dx.doi.org/10.4236/oalib.1101256

[3] Yaglom, I.M. (1979) A Simple Non-Euclidean Geometry and Its Physical Basis. Springer-Verlag, New York. 